\title{
COMO AUMENTAR A PROPORÇÃO DE ESTUDANTES NEGROS NA UNIVERSIDADE?
}

\author{
MARCELO HENRIQUE ROMANO TRAGTENBERG \\ Departamento de Física, Universidade Federal de Santa Catarina - UFSC \\ Grupo de Trabalho de Etnia, Gênero e Classe, Associação dos Professores da UFSC \\ marcelo@fisica.ufsc.br
}

JOÃO LUIZ DORNELLES BASTOS

Mestrando em Epidemiologia - Universidade Federal de Pelotas joao@pilotis.com.br

\section{LINCON HIDEO NOMURA}

Graduado em Odontologia - UFSC

linconhn@brturbo.com

\section{MARCO AURÉLIO PERES}

Departamento de Saúde Pública - UFSC

Grupo de Trabalho de Etnia, Gênero e Classe, Associação dos Professores - UFSC

mperes@ccs.ufsc.br

\section{RESUMO}

Existem diferentes propostas para aumento da população negra na universidade. Com o objetivo de investigar o impacto da adoção de algumas propostas na proporção de negros no ensino superior, a partir dos bancos de dados do vestibular e dos matriculados em 2004 na Universidade Federal de Santa Catarina, foi estudada a distribuição étnico-racial na instituição. Verificou-se baixa proporção de estudantes negros candidatos e aprovados no vestibular e matriculados na referida universidade. A duplicação do número de vagas e a reserva de $50 \%$ das vagas para egressos de escola pública não alteram esse perfil étnico-racial, indicando que políticas sensíveis à cor têm de ser utilizadas para aumentar a proporção de estudantes negros no ensino superior público e contribuir para a redução de desigualdades raciais no Brasil. Foram simuladas diferentes proporções de reservas de vagas: 15\%, 20\% e 5\% de negros, esta última somente para oriundos de escola pública. Em geral, a redução da nota mínima de ingresso em cursos de diferentes níveis de prestígio social é da ordem de $10 \%$ ou menos, não indicando um quadro de expressiva queda da qualidade de ensino.

DISCRIMINAÇÃO RACIAL - DESIGUALDADES SOCIAIS - UNIVERSIDADES - NEGROS 


\section{ABSTRACT}

HOW TO INCREASE THE RATE OF BLACK STUDENTS AT UNIVERSITY? There are different proposals to increase the number of black students at university. Aiming to assess the impact of adopting some of these proposals for the rate of these students in college education, the ethnical and racial distribution in the Federal University of Santa Catarina was studied, based on university admission exams (vestibular) data banks and on the enrollments for the institution in 2004. The research found out that there is a very small number of black students who apply for or are approved in the university admission exam and enrolled in the referred university. Duplication of the number of places and reservation of $50 \%$ of the places for applicants from public schools do not change this ethnical and racial profile, thus indicating that skin-color sensitive policies must be adopted in order to increase the rate of black students attending public universities and to contribute to the reduction of racial inequalities in Brazil. The study simulated different rates for reservations of places: $15 \%$ and $20 \%$ and $5 \%$ of black students, the latter being for those coming from public schools only. In general, the minimum grade for admission to programs of different levels of social prestige was lowered 10\% or less. No sharp loss in the quality of teaching was noticed.

RACIAL DISCRIMINATION - SOCIALLY DISADVANTAGED - UNIVERSITIES - BLACK

Um dos temas mais polêmicos da atualidade brasileira é a adoção de reserva de vagas para negros nas universidades públicas. Assunto menos controverso é a reserva de vagas para alunos oriundos de escolas públicas.

Como se situa historicamente essa questão?

Nossa sociedade estruturou-se antes e após a abolição da escravatura sobre a discriminação de uma parcela que, no início, era a maioria da população e que, hoje, constitui pouco menos da metade dela: a população negra. Estamos denominando negro o agrupamento das categorias preto e pardo, segundo o critério de cor/raça estabelecido pelo Instituto Brasileiro de Geografia e Estatística - IBGE. Em outras palavras, os censos populacionais de 1872 e 1890 registraram cerca de $61 \%$ e $56 \%$ de negros, respectivamente, e o de 2000 estimou em cerca de $45 \%$ a proporção de negros na população brasileira (Telles, 2003).

A imigração branca ocorrida no final do século XIX e início do século $X X$ caracterizou-se como uma política de Estado. Foi incentivada para branquear a população e excluir o negro do mercado de trabalho, tendo como base sua desvalorização em relação ao branco, propugnada pela chamada ideologia do branqueamento (Skidmore, 1974; Azevedo, 1987; Andrews, 1992; Santos, 2001 ; Muller, 2003). 
A partir da década de 30, na mesma época do esforço de constituição de uma identidade nacional, fomentado por Getúlio Vargas em contraposição à política do "café com leite", foi elaborada a identificação do tipo nacional como mestiço. Isso deu origem à ideologia da mestiçagem, que pregava e ainda prega que o Brasil é um país de pessoas mestiças e que este é o ideal, pois o povo brasileiro seria originário de três fontes raciais' (negra, índia e branca), que conviveriam em harmonia. Um dos autores que provavelmente mais contribuiu para a formulação dessa ideologia foi Gilberto Freyre (2004; 2004a).

Sobre esse edifício teórico foi construída a ideologia da democracia racial, segundo a qual as pessoas de cores/raças diferentes são tratadas da mesma forma, pois não haveria aversão mútua entre as cores/raças, que se misturariam e teriam supostamente uma convivência harmoniosa.

As duas ideologias se articularam para negar a existência do racismo no Brasil, pois não existiriam pessoas com cores/raças diferentes e bem definidas e, particularmente, não existiriam negros (somos todos mestiços). Não haveria, portanto, identidade negra, mas um contínuo de cores, do preto ao bran$\mathrm{co}$, e as pessoas seriam tratadas com igualdade.

Após a experiência do racismo nazista da $2^{\text {a }}$ Guerra Mundial, a Unesco financiou, na década de 1950, um estudo acerca do modelo de sociedade em que imperaria uma convivência sem conflitos de raças/cores: a brasileira! Nesse trabalho, várias contribuições (Fernandes, 1965; Bastide, Fernandes, 1971; Pinto, 1998) revelaram o oposto da teoria vigente. Segundo esses pesquisadores, não havia democracia racial, nem convivência harmoniosa de raças/cores no país. Existia discriminação contra negros, um dos frutos da desvalorização racista dessa parcela da população. Foi também constatada a existência de desigualdades raciais, particularmente no mercado de trabalho, em parte derivadas da discriminação. $\bigcirc$ racismo brasileiro, segundo esse estudo, existe e produz discriminação e desigualdade.

Por vários motivos que estão além dos propósitos deste artigo, o estudo de maior impacto sobre desigualdades raciais produzido após o projeto da Unesco, de autoria de Carlos Hasenbalg foi publicado somente em 1979. Mais

I. Não utilizamos neste artigo o conceito de raça no sentido biológico, da existência de diferentes raças, mas na sua acepção social específica do Brasil, em que pessoas com fenótipos não brancos são discriminadas. 
recentemente, a partir dos anos 90 e início da década de 2000, têm sido realizadas outras pesquisas sobre o assunto, das quais citamos apenas algumas delas (Lovell, 1992; Turra, Venturi, 1995; Andrews, 1998; Barros; Beghin, 2002; Paixão, 2003; Telles, 2003; Batista et al., 2004). Órgãos oficiais também têmse debruçado sobre a temática, entre eles o Instituto de Pesquisa Econômica Aplicada - Ipea (Henriques, 200 I ; Ipea, 2005). Todos esses estudos enfatizam a persistente desigualdade racial no Brasil e a desvantagem relativa dos negros nas diversas áreas e ramos de atividade.

Entre as várias formas de combate às desigualdades raciais, tem-se discutido a adoção de cotas ou de critérios étnico-raciais de acesso à universidade. Após a sua formulação, surgiram propostas de cotas para egressos de escola pública, acreditando-se, por um lado, que esta diminuiria a desigualdade racial e, por outro, que egressos de escolas públicas também seriam marginalizados do ensino público superior por serem de famílias de mais baixa renda e terem experimentado pior qualidade no ensino básico.

Mediante esse estudo objetiva-se problematizar o tema e analisar as alternativas de aumento da proporção de estudantes negros no caso de uma universidade pública. Partimos do conhecimento da composição étnico-racial dos alunos de graduação da Universidade Federal de Santa Catarina - UFSC e de simulações do impacto dessas alternativas sobre a composição étnica dos estudantes.

Assim sendo, caracterizamos na próxima seção as desigualdades raciais de forma geral, na educação como um todo e no ensino superior em particular. Em seguida, elaboramos as perguntas que instigaram a pesquisa, relacionadas às políticas de aumento da participação negra no alunado de graduação das universidades públicas, em especial na UFSC. Posteriormente, apresentamos a metodologia utilizada para discutir as propostas de aumento do acesso de oriundos de escolas públicas e de negros, por meio de censo étnico e de simulações de políticas insensíveis à cor, bem como de ações afirmativas: aumento do número de vagas na universidade; adoção de reserva de vagas para egressos de escolas públicas; adoção de reserva de vagas para negros. Por último, descrevemos e discutimos os resultados e fazemos considerações finais. 


\section{DESIGUALDADES ÉTNICO-RACIAIS NO BRASIL: ASPECTOS GERAIS E EDUCAÇÃO}

Uma série de estudos aponta para a existência de profundas e persistentes desigualdades raciais no Brasil, contrariando a ideologia da democracia racial. Abordamos resumidamente nesta seção aspectos de renda, trabalho infantil, habitação, desemprego, saúde, educação, Índice de Desenvolvimento Humano - IDH -, escolaridade média, ensino médio e ensino superior (diplomados e professores).

Estudo do Ipea (Henriques, 200 I) mostrou que entre os 10\% mais pobres da população (indigentes), 70\% são negros e 30\%, brancos. Entre os $10 \%$ mais ricos há $15 \%$ de negros e $85 \%$ de brancos. Em outras palavras, a pobreza é negra e a riqueza é branca.

Nesse mesmo estudo relata-se que o trabalho infantil é maior na população negra. Em 1999, das crianças entre cinco e nove anos, 1,84\% das brancas e 3,03\% das negras trabalhavam; das crianças de 10 a 14 anos, 0, 13\% das brancas trabalhavam contra $0,20 \%$ das negras.

Ainda segundo esse estudo, as habitações da população negra têm maior percentagem de material não-durável, estão mais freqüentemente localizadas em terrenos impróprios, têm maior densidade de moradores, abastecimento de água inadequado e menos esgotos em relação às habitações dos brancos.

Departamento Intersindical de Estatística e Estudos Sócio-Econômicos - Dieese (2002) - divulgou que, nas regiões metropolitanas de Belo Horizonte, Salvador, São Paulo, Porto Alegre, Distrito Federal e Recife, os trabaIhadores negros recebem de $50 \%$ a $67 \%$ do rendimento dos brancos. Por sua vez, o desemprego dos brancos corresponde a $67 \%$ a $75 \%$ do desemprego dos negros.

Na saúde, a situação dos negros brasileiros também é desfavorável. Indicaremos nesta rápida revisão as desigualdades raciais quanto às causas de morte e assistência ao pré-natal e ao parto.

Batista et al. concluíram, em estudo de 2004, sobre as causas de morte no Estado de São Paulo, que

Há uma morte branca que tem como causa as doenças, as quais, embora de diferentes tipos, não são mais do que doenças. Há uma morte negra que não 
tem causa em doenças: são as causas externas, complicações da gravidez e parto, os transtornos mentais e as causas mal definidas. (2004, p.635)

Soares e Borges (2004) levantaram os dados de homicídio e, desagregando por cor/raça e por estado, mostraram que o percentual de assassinatos de negros é duas vezes e meia maior que o de brancos na maioria dos estados brasileiros.

Em pesquisa realizada no município do Rio de Janeiro, verificou-se que as mulheres negras, em relação às brancas, recebem menos anestesia nos partos normais; têm maior risco de perambular por diversas maternidades antes de dar à luz; tendem a sofrer mais agressão física durante a gestação; têm menor escolaridade, menor proporção de trabalho remunerado e possuem um percentual maior de mães adolescentes. As mães negras também manifestam menor satisfação quanto à assistência prestada no pré-natal e no parto (Leal et al., 2005).

Paixão (2003) mostrou que o IDH brasileiro pode ser desagregado por cor/raça. $\mathrm{O} \mathrm{IDH}$ é um índice determinado pela longevidade da população, escolaridade média, alfabetização e renda média per capita. $\mathrm{O}$ IDH brasileiro em 1997 era de 0,739, correspondendo ao $79^{\circ}$ lugar em 174 países, segundo levantamento do Programa das Nações Unidas para o Desenvolvimento PNUD. O IDH da população negra era 0,67| ( $108^{\circ}$ lugar, atrás do Tajiquistão e da África do Sul). Já o da população branca era 0,79l, correspondendo ao $49^{\circ}$ lugar, abaixo do Panamá e acima do México. Esse índice é bem próximo dos países com IDH elevado, acima de 0,8.

No que concerne mais diretamente a este artigo, estamos interessados em identificar a situação atual de exclusão da população negra do ensino superior e quais tipos de políticas seriam indicados para que a situação fosse revertida, ainda que parcial e gradualmente.

Essa exclusão pode ser identificada já no ensino médio. Segundo Petruccelli (2004), 22,7\% dos brancos com 18 anos ou mais concluíram o ensino médio, contra somente 13,3\% dos negros. A escolaridade média dos negros em 1999 era de quatro anos e a dos brancos alcançava 6,3 anos. Por sua vez, em 1999 o analfabetismo atingia 10\% dos brancos e $20 \%$ dos negros.

Em 2000, cerca de 2\% dos negros possuíam diploma universitário em contraposição a $10 \%$ dos brancos. Porém, mais dramática é a constatação do 
aumento da desigualdade racial nas últimas décadas, apesar do crescimento do número de alunos no ensino superior. Telles (2003) mostrou que, entre 1960 e 1999, os brancos diplomados aumentaram de 1,6\% para 10,5\% e os negros aumentaram de $0 \%$ para $2 \%$, baseado nas Pesquisas Nacionais por Amostra de Domicílio - PNADs e nos censos populacionais. Isso indica que a taxa média anual de aumento da titulação dos brancos foi de 0,23\%, enquanto a dos negros foi de $0,05 \%$ (quase cinco vezes menor). Assim, foram os brancos os grandes beneficiários do boom do ensino superior ocorrido entre 1960 a 1999. Este é um exemplo de que uma política de expansão da educação insensível à cor de expansão da educação pode aumentar as desigualdades raciais.

Recentemente, Carvalho (2005) estimou em cerca de $1 \%$ ou menos o número de professores negros em universidades públicas. Isso pode ser conseqüência direta da aludida concentração racial dos diplomas universitários, correspondendo a outro exemplo de que políticas de aumento de vagas para professores em universidades públicas insensíveis à cor podem manter ou aumentar desigualdades raciais.

No campo parlamentar, várias iniciativas focalizaram a questão da desigualdade racial na educação. O deputado federal Abdias do Nascimento propôs, no ano de 1983, o projeto de lei n. 1.332/83 que estabelecia cotas para negros nas universidades. Em 1987, o deputado federal Florestan Fernandes fazia proposta de ação afirmativa para negros e outras populações marginalizadas a ser incluída em um capítulo da Constituição de 1988 (Fernandes, 1989).

Em 1999, o antropólogo José Jorge de Carvalho propunha cotas para negros na Universidade de Brasília - UnB (Carvalho, 2005). Em 2000, o então deputado federal Paulo Paim apresentou o projeto de lei n. 3.198 ou Estatuto da Igualdade Racial, que previa um mínimo de 20\% de cotas para negros nas universidades públicas, além de outras ações afirmativas. Em 8/5/2002, a Comissão de Constituição e Justiça do Senado Federal aprovou substitutivo de Sebastião Rocha a projeto de lei n. 650/l999 do Senador José Sarney, que propõe um mínimo de $20 \%$ de cotas para negros nas universidades, além de programas de assistência estudantil e pedagógica.

Por sua vez, o projeto de lei n. 298/1999, do senador Antero Paes de Barros, determinava que $50 \%$ de todas as vagas das universidades federais fossem destinadas a alunos de escolas públicas. Essa foi uma maneira de tentar colocar a questão como favorecimento da origem escolar (conectada à renda 
baixa) em vez da raça, pois este último tipo de ação afirmativa encontra significativas barreiras na academia e em parcelas da sociedade brasileira, particularmente sua elite e a grande imprensa.

Apesar de todas essas propostas, foi somente após a participação brasileira na $3^{\text {a }}$ Conferência Internacional contra o Racismo, a Xenofobia e Intolerâncias correlatas, realizada em Durban, no ano de 200I, que tomou grande impulso a discussão, na sociedade brasileira, da reparação da população negra mediante ações afirmativas no acesso ao ensino superior por critérios étnicos como cotas ou pontuação. Várias outras ações afirmativas já vinham sendo realizadas, mas centralizaremos nossa atenção naquelas relacionadas com o acesso ao ensino superior.

\section{PERGUNTAS SOBRE A QUESTÃO ÉTNICO-RACIAL}

A implantação de políticas que considerem critérios étnicos de acesso ao ensino superior levanta uma série de questões. Algumas delas serão tratadas neste trabalho. O caso em questão é o da Universidade Federal de Santa Catarina.

I. Qual a composição étnico-racial de vestibulandos e aprovados no vestibular UFSC 2004? A população negra de candidatos está representada na UFSC na mesma proporção que a população atendida pela UFSC?

2. Qual a composição étnico-racial dos vestibulandos e dos matriculados em cursos de graduação da UFSC em 2004?

3. Qual o impacto da adoção de uma política de duplicação das vagas da graduação na proporção de negros na universidade? $\bigcirc$ aumento de vagas traria, por si só, igualdade racial significativamente maior?

4. Qual o impacto da implementação da reserva de $50 \%$ das vagas para egressos de escolas públicas na proporção de negros na universidade? Cotas para a escola pública trariam, por si só, igualdade racial?

5. Qual o impacto sobre a nota mínima de entrada, em cursos de maior ou menor prestígio social, da adoção de vários tipos e percentagens de reserva de vagas, por exemplo, aquelas propostas em projetos de lei? 


\section{MÉTODOS}

A UFSC tem uma estrutura de pesquisa expressiva, estando entre as dez universidades brasileiras com maior número de grupos de pesquisa registrados no Conselho Nacional de Desenvolvimento Científico e Tecnológico CNPq. Possui cerca de 20.500 alunos em 87 opções de cursos de graduação, cerca de 5 mil alunos distribuídos em 50 programas de pós-graduação, dos quais 20 obtiveram conceito 5 ou 6 da Coordenação de Pessoal de Nível Superior - Capes - e pouco mais de mil doutores entre os aproximadamente 1.700 professores efetivos.

O quesito cor/raça foi incluído no questionário socioeconômico do vestibular e na atualização cadastral das matrículas de graduação a partir de 2003, por meio de autodeclaração, por solicitação do Grupo de Trabalho de Etnia, Gênero e Classe da Associação dos Professores da UFSC à Comissão Permanente de Vestibular - Coperve - em maio de 2002. Tornou-se então possível calcular a composição racial dos candidatos, ingressantes e alunos de cada curso da UFSC, já que dispomos dos bancos de dados dos vestibulandos, aprovados e matriculados de 2004.

No questionário do vestibular constam somente as categorias utilizadas pelo IBGE, a saber: branco, preto, pardo, amarelo e indígena. Já no caso das matrículas, além das categorias do IBGE há outra denominada "não-declarado", a fim de evitar conflitos com os que não quiseram se autodeclarar.

O estudo utilizou dois bancos de dados: um do vestibular de 2004, cedido pela Comissão Permanente de Vestibular da UFSC, que totalizou 37.695 candidatos e 3.895 aprovados; e outro das 16.179 matrículas nos cursos de graduação do $2^{\circ}$ semestre de 2004, disponibilizado pelo Núcleo de Processamento de Dados - NPD - da UFSC. Do questionário do vestibular, utilizamos o quesito cor/raça, o curso de opção do candidato, pontuação no vestibular e o tipo de escola cursada no ensino médio. No questionário esse quesito apresentava as categorias: ensino médio somente em escola pública, parcialmente em escola pública, em escola privada, que agregamos em somente pública ou não, para fins de análise. No banco de dados das matrículas foi utilizado apenas o quesito cor/raça. Utilizamos para análise dos dados o programa estatístico Stata, versão 8.0 para Windows.

Consideramos no estudo cursos de maior prestígio social: Medicina, Odontologia, Engenharia Mecânica, Engenharia Elétrica, Administração, Com- 
putação e Psicologia. Cursos de menor prestígio social constituem: Química, Licenciatura em Física noturno, Ciências Biológicas, Geografia noturno, História noturno e Educação Física. Utilizamos uma variante da classificação por prestígio social proposta por Queiroz (2002), que separa os cursos de alto dos de médio/baixo prestígio social. Alternativamente, adotamos as categorias "maior" e "menor prestígio social". Cumpre observar que mesmo sendo considerado curso de menor prestígio social, o de Ciências Biológicas é o quarto com maior relação candidato-vaga, o que explica sua maior seletividade, como poderá ser observado nas análises.

Simulamos o efeito da duplicação do número de vagas nos cursos estudados sobre a composição étnico-racial da seguinte forma: consideramos em cada curso os candidatos aprovados caso houvesse o dobro do número de vagas oferecidas; logo após, calculamos a distribuição étnico-racial desses candidatos.

Em outra simulação avaliamos o impacto étnico-racial da reserva de $50 \%$ das vagas para alunos que cumpriram integralmente o ensino médio em escola pública. Para isso, por exemplo, suponha-se que um curso tenha 100 vagas. Destas, 50 foram preenchidas pelos alunos que cursaram integralmente o ensino médio numa escola pública com as melhores notas no vestibular. As 50 vagas restantes foram preenchidas pelos alunos que cursaram o ensino médio apenas ou parcialmente em escola privada, com as melhores notas no vestibular. Em seguida, calculamos a distribuição étnico-racial desses 100 candidatos classificados.

Simulamos três tipos de reserva de vagas para negros, buscando investigar seu efeito sobre a nota mínima de ingresso em cada curso, para verificar se haveria ou não substancial diminuição dessas notas. São eles: I $5 \%$ ou $20 \%$ das vagas para negros sem distinção de origem escolar, e 5\% das vagas para negros que cursaram todo o ensino médio em escolas públicas.

A escolha das percentagens justifica-se da seguinte forma:

a. I5\% é a percentagem de negros ponderada pelos estados de origem dos candidatos ao vestibular da UFSC. Esses candidatos são de vários estados, majoritariamente de Santa Catarina, São Paulo, Rio Grande do Sul e Paraná. Por exemplo, I2\% da população gaúcha é negra, segundo o Censo de 2000. Então, num cenário de democracia racial em que mil candidatos gaúchos se inscreveram no vestibular, deveria 
haver 120 candidatos negros. Por esse cálculo para os candidatos de outros estados e para os do resto do país, obtivemos cerca de I5\% de estudantes negros que deveriam ingressar na UFSC, na série histórica de 200 I a 2005;

b. $20 \%$ correspondem à proporção reivindicada como mínima pelo Movimento Negro e constam dos projetos de lei dos senadores Paulo Paim e José Sarney. Além disso, seria uma medida de aceleração do processo de democratização racial da sociedade catarinense, pois permitiria que a percentagem de formados negros se aproximasse mais rapidamente da de formados brancos;

c. $5 \%$ é a percentagem proposta no projeto de lei n. 3.627/2004 do Governo Lula, que prevê reserva de $50 \%$ das vagas de cada curso para oriundos do ensino médio público, e, nessas vagas, contempla a percentagem de negros na população estadual. Em Santa Catarina, 9,6\% da população são negros segundo o Censo 2000/IBGE, logo a metade é aproximadamente $5 \%$.

Para encontrar a nota mínima de ingresso referente às reservas de vagas utilizaremos como exemplo o caso de reserva de 15\% para negros num curso com 100 vagas. Nesse curso, a cota corresponde a 15 vagas. Assim, foram selecionados os 15 candidatos autodeclarados negros em ordem decrescente de pontuação no vestibular. A nota do último aprovado é a nota mínima de entrada no curso com essa cota. Observa-se que nenhum curso tem I5\% de autodeclarados negros aprovados no vestibular, o que indica que, para essa percentagem, há sempre redução da nota mínima para entrada nos cursos da UFSC quando aplicada a reserva de vagas.

\section{RESULTADOS E DISCUSSÃO}

A seguir, abordaremos respostas aos questionamentos feitos pela pesquisa.

\section{Representação da população negra nos alunos da UFSC}

Conforme a tabela I, a percentagem dos inscritos na UFSC em 2004, classificados como pretos e pardos foi de 2,2\% e 6,5\%, respectivamente. En- 
tre os aprovados houve I, $1 \%$ de pretos e 6,4\% de pardos. Chamamos a atenção para a redução pela metade na proporção de pretos. A tabela 2 mostra que pretos e pardos representaram, em média, 3,4\% dos matriculados autodeclarados de 2004. Levando em conta que houve 43,2\% de não-declaração, chega-se a um percentual corrigido de pretos ou pardos de 6,0\%. Consideramos, para efeito de análise que a distribuição de não-declarados foi aleatória entre as categorias cor/raça. Essa hipótese é reforçada pelo fato de que,

TABELA I

DISTRIBUIÇÃO DOS CANDIDATOS INSCRITOS E APROVADOS NO CONCURSO VESTIBULAR DA UFSC SEGUNDO COR/RAÇA 2004

\begin{tabular}{l|r|r|r|r}
\hline Cor/raça & \multicolumn{2}{|c|}{ Inscritos } & \multicolumn{2}{c}{ Aprovados } \\
\hline & $\mathrm{N}$ & $\%$ & $\mathrm{n}$ & $\%$ \\
\hline Branca & 33621 & 89,3 & 3534 & 90,7 \\
Preta & 832 & 2,2 & 43 & 1,1 \\
Amarela & 689 & 1,8 & 63 & 1,6 \\
Parda & 2462 & 6,5 & 248 & 6,4 \\
Indígena & 91 & 0,2 & 7 & 0,2 \\
\hline Total & 37695 & 100,0 & 3895 & 100,0 \\
\hline
\end{tabular}

Fonte: UFSC, 2005

TABELA 2

DISTRIBUIÇÃO DOS ALUNOS DE GRADUAÇÃO DA UFSC SEGUNDO COR/RAÇA 2004

\begin{tabular}{l|c|c|c}
\hline \multicolumn{1}{c|}{ Cor/raça } & \multicolumn{3}{|c}{ Calouros e veteranos } \\
\hline & $\mathrm{N}$ & $\%$ & \% corrigido* \\
\hline Branca & 8431 & 52,1 & 91,7 \\
Preta & 149 & 0,9 & 1,6 \\
Amarela & 163 & 1,0 & 1,8 \\
Parda & 407 & 2,5 & 4,4 \\
Indígena & 46 & 0,3 & 0,5 \\
Não declarado & 6983 & 43,2 & - \\
\hline Total & 16179 & 100,0 & 100,0 \\
\hline
\end{tabular}

Fonte: UFSC, 2005.

* Percentual corrigido, assumindo-se que a não-declaração de cor/raça foi aleatória entre os grupos. 
TABELA 3

PROPORÇÃO DE CANDIDATOS INSCRITOS E APROVADOS

NO VESTIBULAR E DE ALUNOS NEGROS NA UFSC 2004

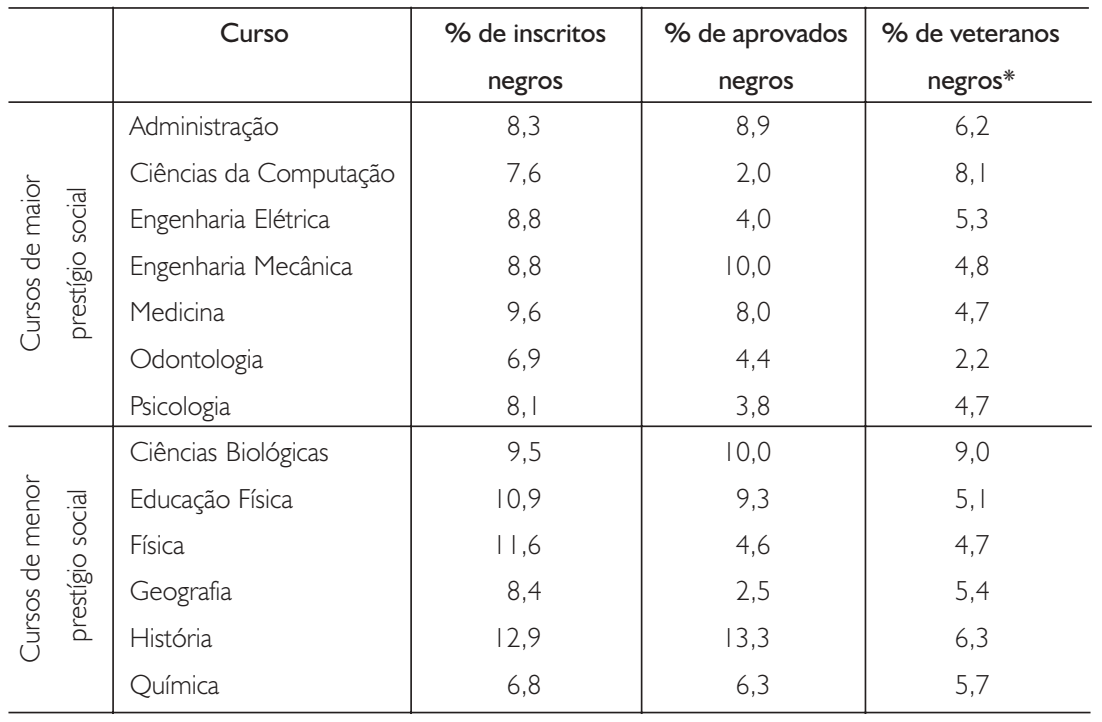

Fonte: UFSC, 2005.

* Percentual corrigido, assumindo-se que a não-declaração de cor/raça foi aleatória entre os grupos.

nos cursos de maior e menor prestígio, há grande flutuação na percentagem de não-declaração, entre 32,8 e 59\%.

O percentual de $6 \%$ de pretos e pardos é significativamente menor que os 15\% esperados num cenário de democracia racial. Há um déficit de 60\% de estudantes negros na UFSC. Outros censos étnicos detectaram desigualdades raciais semelhantes nas universidades federais do Rio de Janeiro, da Bahia, do Maranhão, de Brasília, do Paraná (Queiroz, 2002), na Universidade Federal Fluminense - UFF -, na do Mato Grosso - UFMT (Brandão, Teixeira, 2003) e também na Universidade de São Paulo (Petruccelli, 2004).

\section{Composição étnica por curso}

A tabela 3 mostra a percentagem de candidatos negros inscritos e aprovados no vestibular e matriculados por curso. Os cursos de maior prestígio 
social apresentam percentagens de $2 \%$ a $10 \%$ de alunos negros aprovados em 2004, enquanto nos de menor prestígio a proporção variou de 2,5\% a I3,3\%. Sete dos 13 cursos apresentaram menos de 7,5\% de alunos negros. Apenas o curso de História tem participação próxima à meta de igualdade racial. Este quadro de sub-representação de negros nos cursos é endêmico na UFSC, conforme levantamento que fizemos.

\section{Impacto étnico-racial da duplicação de vagas}

A partir do banco de dados contendo as notas dos candidatos em cada curso no vestibular 2004, simulamos a hipótese que seria oferecido o dobro de vagas e medimos o impacto étnico-racial dessa medida. Os resultados tabulados para o número de vagas atual e o dobro delas estão representados nas figuras I e 2 .

FIGURA I

DUPLICAÇÃO DO NÚMERO DE VAGAS E SEU IMPACTO NA PROPORÇÃO DE ALUNOS NEGROS NOS CURSOS DE MAIOR PRESTÍGIO NO VESTIBULAR DA UFSC 2004

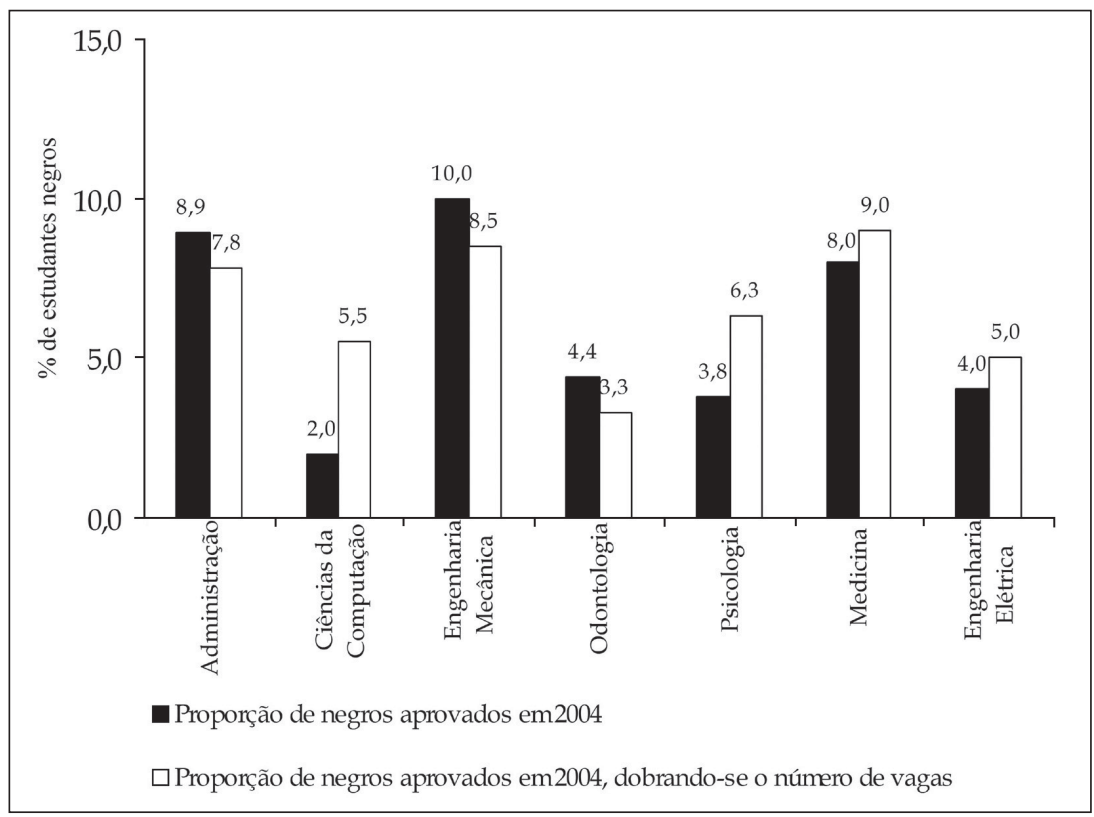

Fonte: Simulação com base nos dados da UFSC, 2005. 
FIGURA 2

DUPLICAÇÃO DO NÚMERO DE VAGAS E SEU IMPACTO NA PROPORÇÃO DE ALUNOS NEGROS NOS CURSOS DE MENOR PRESTÍGIO NO VESTIBULAR DA UFSC 2004

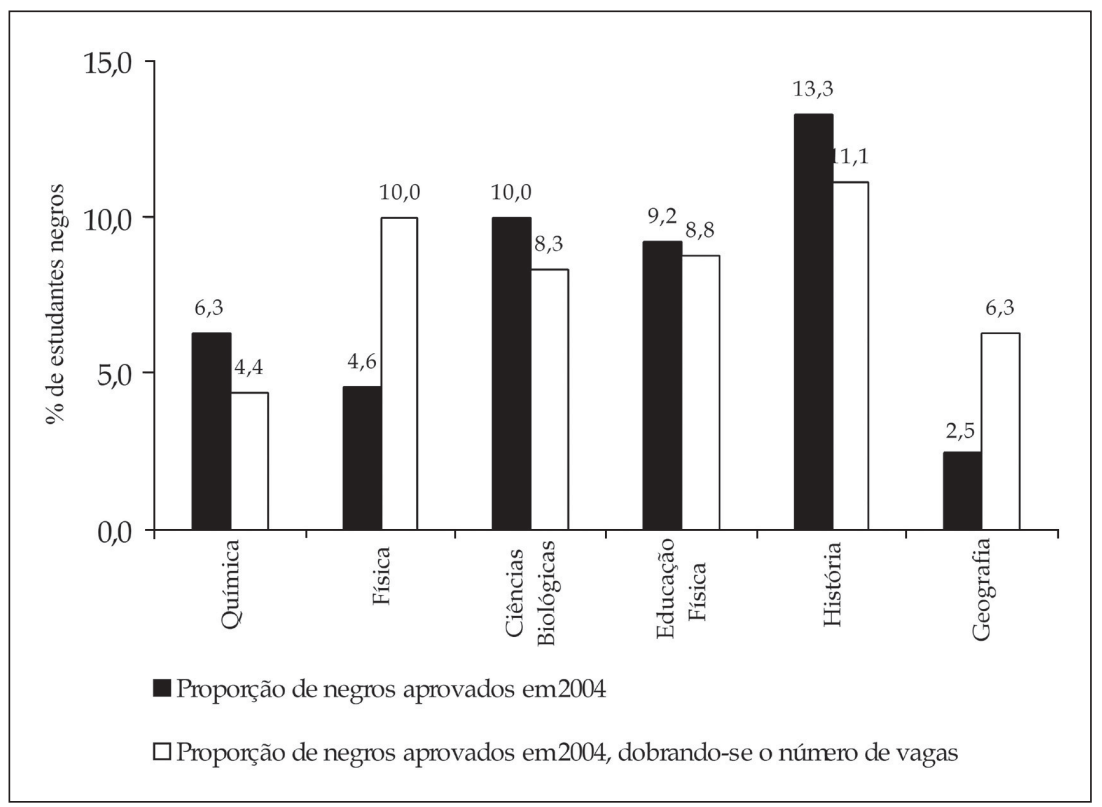

Fonte: Simulação com base nos dados da UFSC, 2005.

Em quatro dos cursos de maior prestígio (Computação, Medicina, Psicologia, Engenharia Elétrica) a percentagem de estudantes negros aumentaria um pouco, sempre bem abaixo dos 15\% no cenário de igualdade racial, como se vê na figura I. O que chama a atenção é que a percentagem de alunos negros diminuiria em Administração (de 8,9\% para 7,8\%), Engenharia Mecânica (de 10\% para 8,5\%) e Odontologia (de 4,4\% para 3,3\%) com a adoção dessa medida.

Nos cursos de menor prestígio social, haveria aumento significativo de alunos negros em Física/Licenciatura noturno (4,6\% para 10\%) e Geografia noturno (de 2,5\% para 6,3\%), conforme a figura 2. No entanto, nos cursos de Ciências Biológicas, História, Química e Educação Física haveria diminuição percentual do número de estudantes negros. Com exceção de História, todos os cursos têm percentuais significativamente inferiores a 15\%. 
De forma geral, pode-se concluir que a duplicação do número de vagas praticamente não altera a aprovação de candidatos negros à UFSC. Isso contraria fortemente a tese que um crescimento de vagas no ensino superior público levaria, de forma automática à igualdade racial e é coerente com a apropriação maior por brancos das vagas do ensino superior de 1960 a 1999 , conforme descrito.

\section{Impacto étnico-racial de cotas de $50 \%$ para escolas públicas}

Consideramos egressos de escola pública aqueles que cursaram integralmente o ensino médio em estabelecimento público, seja ele municipal, estadual ou federal. Conforme a figura 3, entre os cursos de maior prestígio social, três deles mantêm a percentagem de negros, em dois deles esta proporção diminui e em dois aumenta. No curso de Psicologia, o único o qual há significativo aumento dessa percentagem, ela ainda fica abaixo de I5\%.

FIGURA 3

RESERVA DE 50\% DE VAGAS PARA ALUNOS ORIUNDOS DE ESCOLAS PÚBLICAS E SEU IMPACTO NA PROPORÇÃO DE NEGROS NOS CURSOS DE MAIOR PRESTÍGIO NO VESTIBULAR DA UFSC 2004

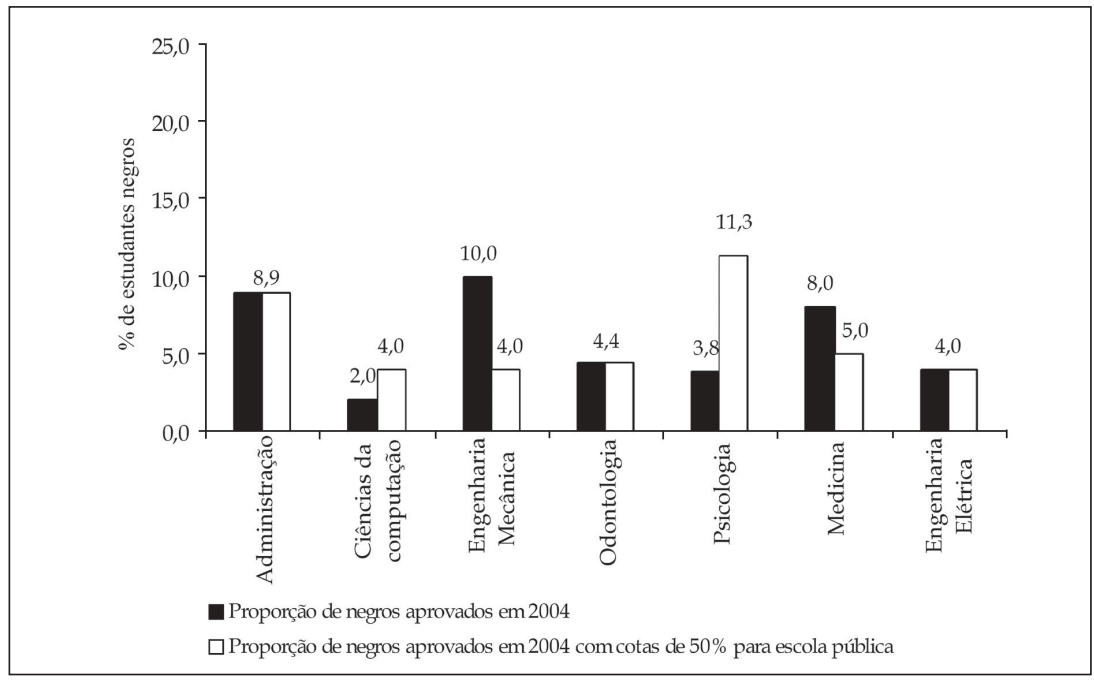

Fonte: Simulação com base nos dados da UFSC, 2005. 
FIGURA 4

RESERVA DE 50\% DE VAGAS PARA ALUNOS ORIUNDOS DE

ESCOLAS PÚBLICAS E SEU IMPACTO NA PROPORÇÃO DE NEGROS

NOS CURSOS DE MENOR PRESTÍGIO NO VESTIBULAR DA UFSC 2005

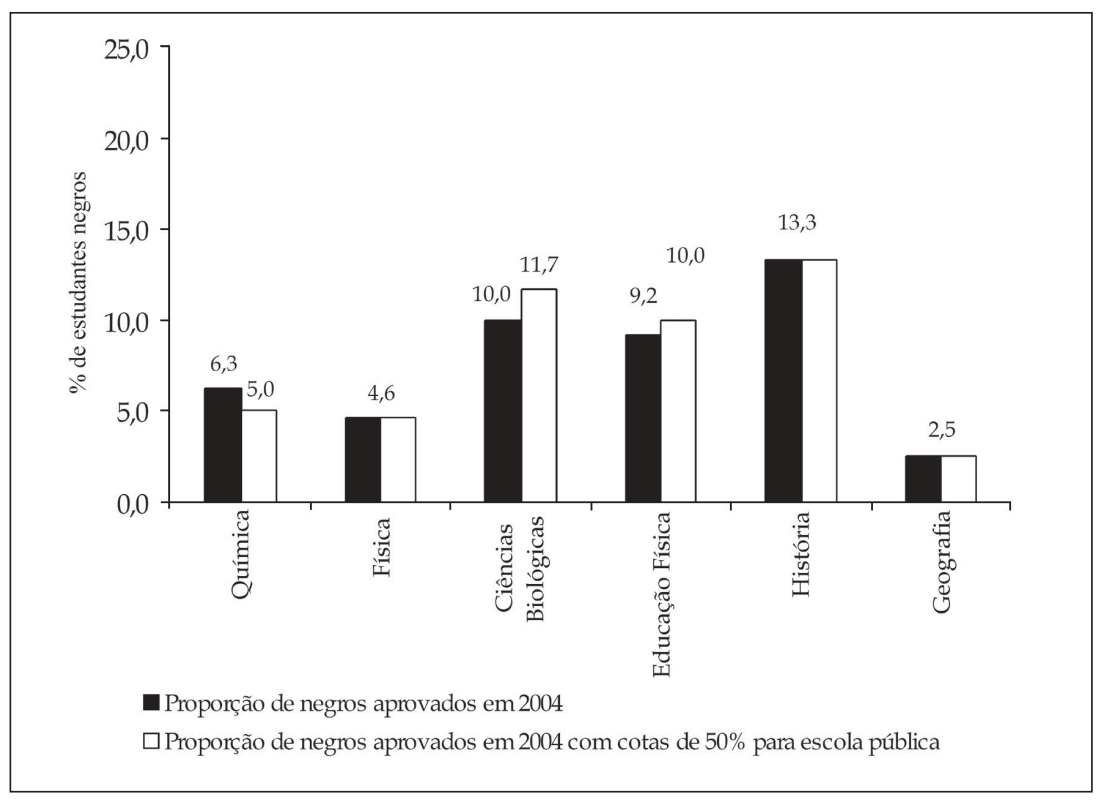

Fonte: Simulação com base nos dados da UFSC, 2005.

No caso de cursos de menor prestígio social, mostrados na figura 4, há pequena diminuição da proporção de negros no curso de Química, a proporção se mantém em outros três e aumenta um pouco em dois cursos. Em todos os cursos, a percentagem de alunos negros é menor do que 15\%. Nos cursos de Física, História e Geografia havia mais de 50\% de estudantes oriundos de escola pública já em 2004, portanto esse tipo de reserva é inócua.

Em resumo, a reserva de $50 \%$ das vagas para oriundos de ensino médio público praticamente não altera a composição étnica da maioria dos cursos estudados, diminuindo em alguns deles a percentagem de alunos negros. Tais dados destroem o mito de que a reserva de vagas para pessoas de renda menor, egressas de escolas públicas, leva à igualdade racial. Esse mito configura-se como uma versão da ideologia da democracia racial aplicada à política de cotas. 


\section{NOTA MÍNIMA DE INGRESSO E COTAS PARA NEGROS}

Consideramos vários cenários de reservas de vagas, tanto para egressos de escolas públicas quanto para negros, e estudamos seu impacto na variação da nota mínima para entrada na UFSC em 2004. A variação dessa nota pode ser explicada pelo seguinte exemplo: se, num curso, a nota do último candidato aprovado no vestibular tradicional for 72 em um máximo de 100, mas se, com reserva de vagas, ela passar a ser 66, então consideraremos uma redução de $6 \%$ na nota. A tabela 4 mostra a redução percentual da nota mínima de ingresso com a adoção das reservas de vagas de 15\% e 20\% para negros ou de $5 \%$ para negros egressos de ensino médio público.

TABELA 4

REDUÇÃO PERCENTUAL NA PONTUAÇÃO MÍNIMA DO VESTIBULAR DA UFSC QUANDO DA RESERVA DE I5\% E 20\% DAS VAGAS PARA ALUNOS NEGROS E 5\% PARA ALUNOS NEGROS ORIUNDOS DE ESCOLA PÚBLICA 2004

\begin{tabular}{|c|c|c|c|c|c|}
\hline & & Curso & $\begin{array}{l}\text { Reserva de } 15 \% \\
\text { para alunos negros }\end{array}$ & $\begin{array}{c}\text { Reserva de } 20 \% \\
\text { para alunos negros }\end{array}$ & $\begin{array}{c}\text { Reserva de } 5 \% \text { para } \\
\text { negros egressos } \\
\text { de escola pública }\end{array}$ \\
\hline \multirow{7}{*}{ 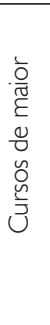 } & \multirow{7}{*}{ 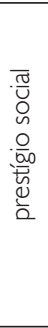 } & Administração & 3,3 & 10,3 & 2,4 \\
\hline & & Ciências da Computação & 8,5 & 13,6 & 8,2 \\
\hline & & Engenharia Elétrica & 10,1 & 12,9 & 12,5 \\
\hline & & Engenharia Mecânica & 3,1 & 9,9 & 24,3 \\
\hline & & Medicina & 2,4 & 3,9 & 13,2 \\
\hline & & Odontologia & 7,8 & $|2|$, & 19,0 \\
\hline & & Psicologia & 6,0 & 7,7 & 7,4 \\
\hline \multirow{6}{*}{\multicolumn{2}{|c|}{ 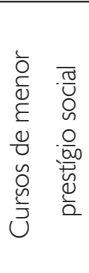 }} & Ciências Biológicas & 2,8 & 5,1 & 7,9 \\
\hline & & Educação Física & 3,5 & 6,5 & 3,5 \\
\hline & & Física & 5,9 & 8,8 & 1,9 \\
\hline & & Geografia & 9,8 & $\mid 1,1$ & 8,8 \\
\hline & & História & 2,1 & 4,9 & 3,0 \\
\hline & & Química & 10,4 & 18,7 & $0,0 *$ \\
\hline
\end{tabular}

Fonte: Simulação com base nos dados da UFSC, 2005

- Neste curso, já são admitidos 5\% de negros egressos de escolas públicas. 
a. Reserva de 15\% de vagas para negros (igual à presença média do negro nos candidatos à UFSC): os cursos de maior prestígio tiveram redução da nota mínima de 2,4\% a 10\%; nos cursos de menor prestígio social a redução foi de 2,1\% a 10,4\%.

b. Reserva de $20 \%$ de vagas para negros (levando em conta que é necessário reparar a enorme deficiência de profissionais e acadêmicos negros na sociedade): a redução da nota mínima foi de 3,9 a I3,6\% nos cursos de maior prestígio e de $4,1 \%$ a $18,7 \%$ nos de menor prestígio social.

c. Reserva de 5\% de vagas para negros egressos de escola pública (conseqüência da aplicação do projeto de lei n. 3.627/2004 proposto pelo Governo Lula, que reserva $50 \%$ das vagas para egressos de escola pública e dentro destas, a percentagem de pretos e pardos na população do estado - em Santa Catarina, segundo o Censo de 2000 há 9,6\% de negros): a redução da nota mínima foi de 2,4 a 24,3\% nos cursos de maior prestígio e de zero a $8,8 \%$ nos de menor prestígio social.

A simulação sobre o impacto na nota mínima de políticas de reserva de vagas foi motivada pela argumentação que ataca as políticas de cotas, supondo que as últimas poderiam baixar severamente a qualidade do ensino na universidade.

A hipótese foi duramente questionada por pesquisa realizada pela Comissão de vestibular da Universidade Estadual de Campinas - Unicamp (Pedrosa, 2005). Esta apontou que alunos de escola pública têm melhor índice de aproveitamento médio ao longo do curso em relação àqueles de escola privada. Conclui-se que não se pode medir o potencial do aluno somente pela nota do vestibular. A referida pesquisa deu origem ao Programa de Ação Afirmativa e Inclusão Social (www.comvest.unicamp.br), que concede 30 pontos a mais para egressos do ensino médio de escola pública e mais dez pontos se ele se autodeclarar negro ou indígena. Não foi feita pesquisa semelhante sobre desempenho de candidatos negros e brancos devido à inexistência de série histórica para o quesito cor/raça na Unicamp, que passou a ser coletado a partir de 2003.

Mesmo não considerando a nota do vestibular como único critério válido de seleção, é necessário dimensionar a diminuição da nota de corte com a 
adoção de políticas afirmativas para que se possa fazer uma avaliação mais profunda do que significa tomar a nota do vestibular como único critério de escoIha para a universidade, especialmente a pública e de qualidade.

Observamos que nos cursos de maior prestígio, reservas de vagas para negros de $15 \%$ ou 20\% têm redução de 2,4 a 13,6\% da nota mínima, algo que não parece desastroso. Observa-se que, em vários cursos da Unicamp, a pontuação dada a mais para egressos de escola pública e negros é da mesma magnitude: cerca de 40 pontos em 400 - Pedagogia - a 650 - Medicina - notas de corte do vestibular 2005, conforme Pedrosa (2005). O grande mérito de uma reserva de $20 \%$ seria o de tentar reparar profundas desigualdades entre negros e brancos, pois avançaria em direção à igualdade racial. Em cursos em que se julga que uma diminuição maior que $10 \%$ da nota mínima poderia permitir o ingresso de pessoas com dificuldade bem maior de permanecer na universidade, seria possível conjugar política de reserva com limite na redução da nota mínima de entrada.

Atrevemos-nos a formular a hipótese de que as escolas freqüentadas pelos negros oferecem ensino de Matemática, Física e Química de pior qualidade que a dos brancos, em média, o que levaria os estudantes negros a obterem menos pontos para as engenharias e o curso de Química. Essa hipótese, no entanto, deveria ser testada em outro estudo.

A proposta governamental de reserva de $5 \%$ das vagas da UFSC para alunos negros de escolas públicas levaria, em alguns cursos, a uma redução um pouco maior da nota mínima, que só é significativa no caso da Engenharia Mecânica (24,3\%) e da Odontologia (19\%). O argumento contrário de maior peso contra essa proposta é a pequena percentagem de negros que ela atende na UFSC, que deveria ser de I5\% num quadro de democracia racial.

\section{CONSIDERAÇÕES FINAIS}

De forma geral, detectamos na UFSC desigualdades raciais na composição do corpo discente e da entrada no vestibular. Observamos fortes evidências que políticas de ampliação de vagas cegas à cor e à renda manterão, em termos gerais, as mesmas desigualdades raciais, assim como políticas de ação afirmativa, baseadas em reserva de vagas para a escola pública. Isso indica que a cor/raça funciona como um gerador de desigualdades no acesso ao ensino 
superior independente da renda, que é genericamente associada aos alunos de escola pública.

São necessárias políticas de reserva de vagas sensíveis à cor para que a composição dos alunos de graduação seja capaz de impulsionar maior igualdade racial no interior da universidade e entre os profissionais por ela formados. Não simulamos nenhuma política de pontuação por pertencimento étnico como a atualmente adotada no vestibular da Unicamp. Isso seria objeto de outra pesquisa.

Com maior fundamentação, podemos afirmar, portanto, que nossos resultados sugerem a necessidade de conjugar aumento de vagas com ações afirmativas emergenciais, tais como cotas percentuais ou pontuação por pertencimento étnico-racial para negros, para se obter melhoras substanciais na igualdade racial quanto ao acesso ao ensino superior em expansão.

Estudos com metodologia semelhante deveriam ser realizados nos demais estados, para que os resultados possam ser estendidos para o Brasil como um todo e, assim, subsidiem políticas de ações afirmativas.

\section{REFERÊNCIAS BIBLIOGRÁFICAS}

ANDREWS,G. R. Desigualdade racial no Brasil e nos Estados Unidos: uma comparação estatística. Estudos Afro-Asiáticos, v.22, p.47-83, 1992.

Negros e brancos em São Paulo ( 1888-1988). Bauru: Sagrado Coração, 1998

AZEVEDO, C. M. M. Onda negra, medo branco: o negro no imaginário das elites - século XIX. Rio de Janeiro: Paz e Terra, 1987

BARROS, L. B.; BEGHIN, N. B. Desigualdades raciais no Brasil: um balanço da intervenção governamental. Brasília: Ipea, 2002.

BASTIDE, R.; FERNANDES, F. Brancos e negros em São Paulo. São Paulo: Companhia Editora Nacional, 1971

BATISTA, L. E. et al. A Cor da morte: causas de óbito segundo características de raça no Estado de São Paulo, 1999 a 200 I. Revista de Saúde Pública, v.38, n.5, p.630-636, 2004.

BRANDÃO, A. A. P.; TEIXEIRA, M. P. Censo étnico-racial da Universidade Federal Fluminense e Universidade Federal do Mato Grosso. Niterói: EdUFF, 2003 
CARVALHO, J. J. Inclusão étnica e racial no Brasil: a questão das cotas no ensino superior. São Paulo: Attar, 2005.

DEPARTAMENTO INTERSINDICAL DE ESTATÍSTICA E ESTUDOS SÓCIO-ECONÔMICOS. A Desigualdade racial no mercado de trabalho. São Paulo: Dieese, nov. 2002.

FERNANDES, F. A Integração do negro na sociedade de classes. São Paulo: Dominus; USP, 1965.

Sugestão de dispositivos constitucionais para o esporte, a educação, o lazer e a cultura. In: FERNANDES, F. A Educação como ato político-partidário. São Paulo: Cortez, 1989. p. $|6|-174$.

FREYRE, G. Casa-grande \& senzala. São Paulo: Global Editora, 2004.

Sobrados \& mocambos. São Paulo: Global Editora, 2004a.

HASENBALG, C. A. Discriminação e desigualdades raciais no Brasil. Rio de Janeiro: Graal, 1979.

HENRIQUES, R. Desigualdade racial no Brasil: evolução das condições de vida na década de 90. Rio de Janeiro: Ipea, 200I.

IPEA. Radar social. Brasília: 2005. Disponível em: www.ipea.gov.br. Acesso em: 3 I jul. 2005.

LEAL, M. C., et al. Desigualdades raciais, sociodemográficas e na assistência ao pré-natal e ao parto, 1999-200 I. Revista de Saúde Pública, v.39, n. I, p. I00-1007, 2005.

LOVELL, P. A. Raça, classe e gênero e discriminação salarial no Brasil. Estudos Afro-Asiáticos, v.22, p.85-98, 1992.

MULLER, M. L. Professoras negras no Rio de Janeiro: história de um branqueamento. In: OLIVEIRA, I. Relações raciais e educação. Rio de Janeiro: DP\&A, 2003. p.73-106.

PAIXÃO, M. Desenvolvimento humano e relações raciais. Rio de Janeiro: DP\&A, 2003.

PEDROSA, R. H. L. Em igualdade de condições, alunos de graduação da Unicamp que estudaram na rede pública têm desempenho acadêmico superior. 2005. Disponível em: http://www.comvest.unicamp.br/vest2004/desempenho_publica.pdf. Acesso em: 3I jul. 2005.

PETRUCCELLI, J. L. Mapa da cor no ensino superior brasileiro. Rio de Janeiro: Programa Políticas da Cor na Educação Brasileira/UERJ, 2004.

PINTO, L. A. C. O Negro no Rio de Janeiro: relações de raças em uma sociedade em mudança. Rio de Janeiro: Editora da UFRJ, 1998. 
Como aumentar a proporção...

QUEIROZ, D. M. O Negro na universidade. Salvador: Novos Toques, 2002.

SANTOS, H. A Busca de um caminho para o Brasil: a trilha do círculo vicioso. São Paulo: Senac, 2001.

SKIDMORE, T. Black into white: race and nationality in Brazilian thought. New York: Oxford University Press, 1974.

SOARES, G. A. D.; BORGES, D. A Cor da morte. Revista Ciência Hoje, v.35, n.209, p.26, 2004.

TELLES, E. Racismo à brasileira: uma nova perspectiva sociológica. Rio de Janeiro: Relume Dumará, 2003.

TURRA, C.; G. VENTURI. Racismo cordial: a mais completa análise do preconceito de cor no Brasil. São Paulo: Ática, 1995.

Recebido em: outubro 2005

Aprovado para publicação em: novembro 2005 